\title{
AN EXISTENCE THEOREM FOR A VOLTERRA INTEGRAL EQUATION WITH DEVIATING ARGUMENTS*
}

\author{
K. Balachandran and S. Ilamaran \\ Department of Mathematics \\ Bharathiar University \\ Coimbatore-641 046 \\ Tamil Nadu, India
}

\begin{abstract}
An existence theorem is proved for a nonlinear Volterra integral equation with deviating arguments.

Key words: Existence of solution, Volterra integral equation, Deviating arguments, Schauder fixed point theorem.
\end{abstract}

AMS subject classification: 45D05.

\section{INTRODUCTION}

The theory of nonlinear Volterra integral equations with deviating arguments and functional integral equations have been studied by many authors [1,2,5,6]. Banas [4] has proved an existence theorem for functional integral equations and Balachandran [1] has proved an existence theorem for a nonlinear Volterra integral equation with deviating argument. In this paper we shall derive a set of sufficient conditions for the existence of a solution of nonlinear Volterra integral equations with deviating arguments. This result is a generalization of the results in $[1,4]$.

\section{BASIC ASSUMPTIONS}

Let $p(t)$ be a given continuous function defined on the interval $[0, \infty)$ and taking real positive values. Denote $C\left([0, \infty), p(t): R^{n}\right)$ by $C_{p}$, the set of all continuous functions from $[0, \infty)$ into $\boldsymbol{R}^{n}$ such that

$$
\sup \{|x(t)| p(t): t \geq 0\}<\infty .
$$

It has been proved [7] that $C_{p}$ forms a real Banach space with regard to the norm

$$
\|x\|=\sup \{|x(t)| p(t): t \geq 0\} .
$$

If $x \in C_{p}$ then we will denote by $\omega^{T}(x, \varepsilon)$ the usual modulus of continuity of $x$ on the interval $[0, T]$, that is,

\footnotetext{
* Received: October 1989, Revised: March 1990.
} 


$$
\omega^{T}(x, \varepsilon)=\sup \{|x(t)-x(s)|:|t-s| \leq \varepsilon, t, s \in[0, T]\} .
$$

Our existence theorem is based on the following lemma.

Lemma (See [3].): Let $E$ be a bounded set in the space $C_{p}$. If all functions belonging to $E$ are equicontinuous on each interval $[0, \mathrm{~T}]$ and

$$
\lim _{T \rightarrow \infty}\{|x(t)| p(t): t \geq T\}=0
$$

uniformly with respect to $E$, then $E$ is relatively compact in $C_{p}$.

Consider the nonlinear Volterra integral equation with deviating arguments (1) $x(t)=G(x) g\left(t, x\left(h_{1}(t)\right), x\left(h_{2}(t)\right), \ldots, x\left(h_{n}(t)\right)\right)+\int_{0}^{t} K\left(t, s, x\left(H_{1}(s)\right), \ldots, x\left(H_{m}(s)\right)\right) d s$ where $x, H$ and $K$ are $n$-vectors and $G$ is a real-valued function. Assume the following conditions.

(i) Let $\Delta=\{(t, s): 0 \leq s \leq t<\infty\}$. The kernel $K: \Delta \times \boldsymbol{R}^{n m} \rightarrow \boldsymbol{R}^{n}$ is continuous and there exist continuous functions $m: \Delta \rightarrow[0, \infty), a:[0, \infty) \rightarrow(0, \infty)$, and $b:[0, \infty) \rightarrow[0, \infty)$ such that

$$
\left|K\left(t, s, x_{1}, x_{2}, \ldots, x_{m}\right)\right| \leq m(t, s)+a(t) b(s) \sum_{i=1}^{m}\left|x_{i}\right|
$$

for all $(t, s) \in \Delta$ and $\left(x_{1}, x_{2}, \ldots, x_{m}\right) \in R^{n m}$.

In order to formulate other assumptions let us define $L(t)=\int_{0}^{t} a(s) b(s) d s, \quad t \geq 0$; furthermore, let us take an arbitrary number $M>0$ and consider the space $C_{p}$ with $p(t)=\left[a(t) e^{M L(t)+t}\right]^{-1}$.

(ii) There exists a constant $A>0$ such that for any $t \in[0, \infty)$ the following inequality holds.

$$
\int_{0}^{t} m(t, s) d s \leq A a(t) e^{M L(t)}
$$

(iii) For $i=1,2, \ldots, n$ the functions $h_{i}:[0, \infty) \rightarrow[0, \infty)$ are continuous, $h_{i}(0)=0$, $h_{i}(t) \leq t$ for $t \geq 0$ and there exists a positive real number $B_{i}$ such that $a\left(h_{i}(t)\right) \leq B_{i} a(t)$.

(iv) G: $C_{p} \rightarrow[0, \infty)$ is continuous and bounded. Assume $|G(x)| \leq k_{1}$ where $k_{1}$ is a positive constant.

(v) The function g: $[0, \infty) \times \boldsymbol{R}^{n^{2}} \rightarrow \boldsymbol{R}^{n}$ is continuous and satisfies the conditions

$$
\left|g\left(t, x_{1}, x_{2}, \ldots, x_{n}\right)-g\left(t, y_{1}, y_{2}, \ldots, y_{n}\right)\right| \leq \sum_{i=1}^{n} \alpha_{i}(t)\left|x_{i}-y_{i}\right|
$$

where $\alpha_{i}(t)$ is continuous such that

$$
\alpha_{i}(t) \leq e^{M\left[L(t)-L\left(h_{i}(t)\right)\right]} \text { for } t \geq 0 \text {, for } i=1,2, \ldots, n \text { and }|g(t, 0, \ldots, 0)| \leq a(t) e^{M L(t)} .
$$


(vi) For $i=1,2, \ldots, m$, the functions $H_{i}:[0, \infty) \rightarrow[0, \infty)$ are continuous and satisfy the following conditions:

$$
L\left(H_{i}(t)\right)-L(t) \leq N_{i}
$$

where $N_{i}$ is a positive constant, and

$$
a\left(H_{i}(t)\right) / a(t) \leq(M / m)\left[1-k_{1}(1+B)-A\right] e^{-M N_{i}}
$$

where $\mathrm{B}=\sum_{\mathrm{i}=1}^{\mathrm{n}} B_{i}$ and we assume $k_{1}(1+B)+A<1$.

\section{EXISTENCE THEOREM}

Theorem: Assume that the hypotheses (i) through (vi) hold; then equation (1) has at least one solution $x$ in the space $C_{p}$ such that $|x(t)| \leq a(t) e^{M L(t)}$ for any $t \geq 0$.

Proof: Define a transformation $F$ in the space $C_{p}$ by

$$
\begin{aligned}
(F x)(t)= & G(x) g\left(t, x\left(h_{1}(t)\right), x\left(h_{2}(t)\right), \ldots, x\left(h_{n}(t)\right)\right) \\
& +\int_{0}^{t} K\left(t, s, x\left(H_{1}(s)\right), \ldots, x\left(H_{m}(s)\right)\right) d s .
\end{aligned}
$$

From our assumptions we observe that $(F x)(t)$ is continuous on the interval $[0, \infty)$. Define the set $E$ in $C_{p}$ by

$$
E=\left\{x \in C_{p}:|x(t)| \leq a(t) e^{M L(t)}\right\} .
$$

Clearly $E$ is nonempty, bounded, convex, and closed in $C_{p}$. Now we prove that $F$ maps the set $E$ into itself. Take $x \in E$. Then from our assumptions we have

$$
\begin{aligned}
|(F x)(t)| \leq & |G(x)|\left|g\left(t, x\left(h_{1}(t)\right), \ldots, x\left(h_{n}(t)\right)\right)\right|+\int_{0}^{t}\left|K\left(t, s, x\left(H_{1}(s)\right), \ldots, x\left(H_{m}(s)\right)\right)\right| d s . \\
\leq & k_{1}\left|g\left(t, x\left(h_{1}(t)\right), \ldots, x\left(h_{n}(t)\right)\right)-g(t, 0, \ldots, 0)\right|+k_{1}|g(t, 0, \ldots, 0)|+\int_{0}^{t} m(t, s) d s \\
& +a(t) \int_{0}^{t} b(s) \sum_{i=1}^{m}\left|x\left(H_{i}(s)\right)\right| d s \\
\leq & k_{1} \sum_{i=1}^{n} \alpha_{i}(t)\left|x\left(h_{i}(t)\right)\right|+\mathrm{k}_{1} \mathrm{a}(t) e^{M L(t)}+A a(t) e^{M L(t)} \\
& +\mathrm{a}(t) \int_{0}^{t} \mathrm{~b}(\mathrm{~s}) \sum_{i=1}^{m} \mathrm{a}\left(H_{i}(s)\right) e^{M L\left(H_{i}(s)\right)} d s \\
\leq & k_{1} \sum_{i=1}^{n} \mathrm{e}^{M\left[L(t)-L\left(h_{i}(t)\right)\right]} a\left(h_{i}(t)\right) e^{M L\left(H_{i}(t)\right)}+k_{1} a(t) e^{M L(t)}+A a(t) e^{M L(t)}
\end{aligned}
$$




$$
\begin{aligned}
& +a(t)\left(\left[1-k_{1}(1+B)-A\right] / m\right) \sum_{i=1}^{m} e^{-M N_{i}} \int_{0}^{t} M b(s) a(s) e^{M N_{i}} e^{M L(s)} d s \\
\leq & k_{1} B a(t) e^{M L(t)}+k_{1} a(t) e^{M L(t)}+A a(t) e^{M L(t)}+a(t)\left[1-k_{1}(1+B)-A\right] e^{M L(t)} \\
= & a(t) e^{M L(t),}
\end{aligned}
$$

which proves that $F E$ is a subset of $E$.

Now we want to prove that $\mathrm{F}$ is continuous on the set $\mathrm{E}$. In order to do this we take $\mathrm{F}=F_{1}+F_{2}$, where

$$
\begin{aligned}
\left(F_{1} x\right)(t) & =G(x) g\left(t, x\left(h_{1}(t)\right), \ldots, x\left(h_{n}(t)\right)\right) \\
\text { and } \quad\left(F_{2} x\right)(t) & =\int_{0}^{t} K\left(t, s, x\left(H_{1}(s)\right), \ldots, x\left(H_{m}(s)\right)\right) d s .
\end{aligned}
$$

We shall prove the continuity of $F_{1}$ and $F_{2}$ separately. Let us fix $\varepsilon>0$ and take $x, y \in E$ such that $\|x-y\| \leq \varepsilon$. We have

$$
\begin{aligned}
& \left\|F_{1} x-F_{1} y\right\| \leq k_{1} \sup \left\{\mid g\left(t, x\left(h_{1}(t)\right), \ldots, x\left(h_{n}(t)\right)\right)\right. \\
& \text { - } \left.g\left(t, y\left(h_{1}(t)\right), \ldots, y\left(h_{n}(t)\right)\right) \mid \cdot\left[a(t) \mathrm{e}^{M L(t)+t}\right]^{-1}: t \geq 0\right\} \\
& +|G(x)-G(y)| \sup \left\{\left|g\left(t, y\left(h_{1}(t)\right), \ldots, y\left(h_{n}(t)\right)\right)\right| \cdot\left[a(t) \mathrm{e}^{M L(t)+t}\right]^{-1}: t \geq 0\right\} \\
& \leq k_{1} \sum_{i=1}^{n} \sup \left\{\alpha_{i}(t)\left|x\left(h_{i}(t)\right)-y\left(h_{i}(t)\right)\right|\left[a(t) e^{M L(t)+t}\right]^{-1}: t \geq 0\right\} \\
& +|G(x)-G(y)| \sup \left\{\left|g\left(t, y\left(h_{1}(t)\right), \ldots, y\left(h_{n}(t)\right)\right)-g(t, 0, \ldots, 0)\right| \cdot\left[a(t) \mathrm{e}^{M L(t)+t}\right]^{-1}: t \geq 0\right\} \\
& +|G(x)-G(y)| \sup \left\{\mid g(t, 0, \ldots, 0) \cdot\left[a(t) \mathrm{e}^{M L(t)+t}\right]^{-1}: t \geq 0\right\} \\
& \leq k_{1} \sum_{i=1}^{n} B_{i} \sup \left\{\left|x\left(h_{i}(t)\right)-y\left(h_{i}(t)\right)\right|\left[a\left(h_{i}(t)\right)\right]^{-1} e^{M\left[L(t)-L\left(h_{i}(t)\right)\right]} e^{-M L(t)-t}: t \geq 0\right\}
\end{aligned}
$$

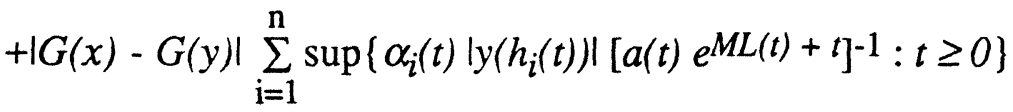

$$
\begin{aligned}
& +|G(x)-G(y)| \sup \left\{e^{-t}: t \geq 0\right\}
\end{aligned}
$$

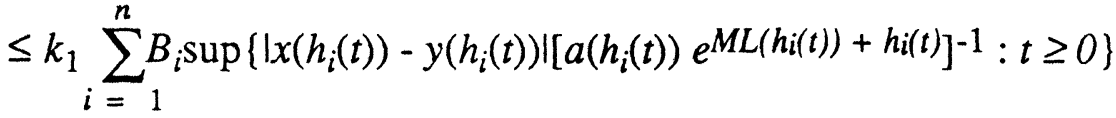

$$
\begin{aligned}
& +|G(x)-G(y)| \sum_{\mathrm{i}=1}^{\mathrm{n}} \sup \left\{a\left(h_{i}(t)\right) e^{M L(t)}\left[a(t) e^{M L(t)+t]-1}: t \geq 0\right\}+|G(x)-G(y)|\right. \\
& \leq k_{1} B\|x-y\|+B|G(x)-G(y)|+|G(x)-G(y)| \text {. }
\end{aligned}
$$

This implies that $F_{1}$ is continuous in view of $(i v)$.

Now we prove that $F_{2}$ is continuous on the set $E$. For this let us fix $\varepsilon>0$ and $x, y$ $\in E$ such that $\|x-y\| \leq \varepsilon$. Further, let us take an arbitrary fixed $T>O$. In view of $(i)$ and $(v i)$ the function $K\left(t, s, x_{1}, \ldots, x_{m}\right)$ is uniformly continuous on 


$$
[0, T] \times[0, T] \times\left[-r\left(H_{1}(T)\right), r\left(H_{2}(T)\right)\right] \times \ldots \times\left[-r\left(H_{m}(T)\right), r\left(H_{m}(T)\right)\right]
$$

$$
\text { where } r(T)=\max \left\{a(s) e_{t}^{M L(s)}: s \in[0, T] \text {. Thus, we have for } t \in[0, T]\right.
$$

$$
\begin{aligned}
/\left(F_{2} x\right)(t)-\left(F_{2} y\right)(t) / \leq & \int_{o}^{t} K\left(t, s, x\left(H_{1}(s)\right), \ldots, x\left(H_{m}(s)\right)\right. \\
& -K\left(t, s, y\left(H_{1}(s)\right), \ldots, y\left(H_{m}(s)\right) / d s\right. \\
& \leq \beta(\varepsilon)
\end{aligned}
$$

where $\beta(\varepsilon)$ is some continuous function such that $\lim _{\varepsilon \rightarrow 0} \beta(\varepsilon)=0$. Further, let us take $t \geq T$. Then we have

$$
\begin{aligned}
& \begin{aligned}
/\left(F_{2} x\right)(t)-\left(F_{2} y\right)(t) / & \leq /\left(F_{2} x\right)(t) /+\mid\left(F_{2} y\right)(t) / \\
& \leq 2 a(t) e^{M L(t)}
\end{aligned} \\
& \text { and } /\left(F_{2} x\right)(t)-\left(F_{2} y\right)(t) / p(t) \leq 2 e^{-t}
\end{aligned}
$$

Hence for sufficiently large $T$ we have

$$
/\left(F_{2} x\right)(t)-\left(F_{2} y\right)(t) / p(t) \leq \epsilon
$$

By (3) and (4) we get that $F_{2}$ is continuous on the set $E$. Hence $F=F_{1}+F_{2}$ is continuous on $E$.

Now we prove that $F E$ is relatively compact. For every $x \in E$ we have $F x \in E$ which gives $|(F x)(t)| p(t) \leq e^{-t}$. Hence $\lim _{\mathrm{T} \rightarrow \infty} \sup \{|(F x)(t)| p(t): t \geq T\}=0$ uniformly with respect to $x \in E$.

Furthermore, let us fix $\varepsilon>0$ and $T>0$; and let $t, s \in[0, T]$ such that $|t-s| \leq \varepsilon$. Then for $x \in E$, we have

$$
\begin{aligned}
/(F x)(t)-(F x)(s) / \leq & / G(x) / / g\left(t, x\left(h_{1}(t)\right), \ldots, x\left(h_{n}(t)\right)\right) \\
& -g\left(s, x\left(h_{1}(s)\right), \ldots, x\left(h_{n}(s)\right) /\right. \\
& +/ \int_{o}^{t} K\left(t, u, x\left(H_{1}(u)\right), \ldots, x\left(H_{m}(u)\right) d u\right. \\
& -\int_{o}^{s} K\left(s, u, y\left(H_{1}(u)\right), \ldots, y\left(H_{m}(u)\right) d u /\right.
\end{aligned}
$$




$$
\begin{aligned}
& \leq k_{1} \omega^{T}(g, \varepsilon)+/ \int_{o}^{t} K\left(t, u, x\left(H_{1}(u)\right), \ldots, x\left(H_{m}(u)\right) d u\right. \\
& -\int_{o}^{s} K\left(t, u, x\left(H_{1}(u)\right), \ldots, x\left(H_{m}(u)\right)\right) d u / \\
& +/ \int_{o}^{s} K\left(t, u, x\left(H_{1}()\right), \ldots, x\left(H_{m}(u)\right)\right) d u \\
& -\int_{o}^{s} K\left(s, u, x\left(H_{1}(u)\right), \ldots, x\left(H_{m}(u)\right)\right) d u / \\
& \leq k_{1} \omega^{T}(g, \varepsilon)+\int_{s}^{t} / K\left(t, u, x\left(H_{1}(u)\right), \ldots, x\left(H_{m}(u)\right)\right) / d u \\
& +\int_{o}^{s} / K\left(t, u, x\left(H_{1}(u)\right), \ldots, x\left(H_{m}(u)\right)\right) \\
& -K\left(s,, x\left(H_{1}(u)\right), \ldots, x\left(H_{m}(u)\right)\right) / d u \\
& \leq k_{1} \omega^{T}\left(g, \varepsilon+\varepsilon \max \left\{m(t, u)+a(t) b(u) \sum_{i=1}^{m} \mid x\left(H_{i}(u) /: o \leq u \leq t \leq T\right\}\right.\right. \\
& +T \omega^{T}(K, \varepsilon)
\end{aligned}
$$

This tends to zero as $\varepsilon \rightarrow 0$. Thus $F E$ is equicontinuous on $[0, T]$.

Therefore from the lemma $F E$ is relatively compact. Thus the Schauder fixed point theorem guarantees that $F$ has a fixed point $x \in E$ such that $(F x)(t)=x(t)$. Hence the theorem holds.

EXAMPLE: Consider the following nonlinear integral equation:

$$
x(t)=(1 / 8) t \sin x(t / 2)+\int_{0}^{t}\left[t s+\left(t^{3}+(1 / 4)\right) x(s / 3)\right] d s
$$

This is clearly of the form (1) and satisfies all the conditions (i) to (vi) with 


$$
\begin{aligned}
& m=n=1, G(x)=1 / 8, g(t, x)=t \sin x \\
& K(t, s, x)=t s+\left(t^{3}+(1 / 4)\right) x \\
& m(t, s)=t s, a(t)=t^{3}+(1 / 4), b(s)=1 \\
& \alpha_{I}(t)=t, h_{l}(t)=t / 2, H_{l}(t)=t / 3, \\
& M=16, A=1 / 2, B=1, k_{1}=1 / 8, N_{1}=1 / 16
\end{aligned}
$$

Therefore from our existence theorem the equation (5) has at least one solution $x$ in the space $C_{p}$ such that

$$
|x(t)| \leq\left(t^{3}+1 / 4\right) e^{4\left(t^{4}+t\right)} \text { for any } t \geq 0
$$

\section{REFERENCES}

[1] Balachandran, K., Existence of Solution for Nonlinear Volterra Integral Equation with Deviating Argument, J. Math. Phy. Sci., 23(1989), 201205.

[2] Banas, J., An Existence Theorem for Nonlinear Volterra Integral Equation with Deviating Argument, Rendiconti del Circolo Mathematico di Palermo, Series 2, 35(1986), 82-89.

[3] Banas. J. and Goebel, K., Measure of Noncompactness in Banach Spaces, Marcel Dekkar Inc., New York (1980).

[4] Banas, J., On Solutions of Some Functional Integral Equations, Bull. Inst. Math. Acad. Sinica, 12(1984), 23-30. 
[5] Brauer, F., A Nonlinear Variation of Constant Formula for Volterra Equations, Math. Systems Theory, 6 (1972), 226-234.

[6] Burton, T.A., Volterra Integral and Differential Equations, Academic Press, New York, (1983).

[7] Corduneanu, C., Integral Equations and Stability of Feedback Systems, Academic Press, New York (1973).

[8] Kartsatos, A.G., Existence of Bounded Solutions and Asymptotic Relationships for Nonlinear Volterra Integral Equations, Math. Systems Theory 8, (1974), 266-275.

[9] Lakshmikanthem, V. and Leela, S., Differential and Integral Inequalities, Vol. I, Academic Press, New York (1969). 


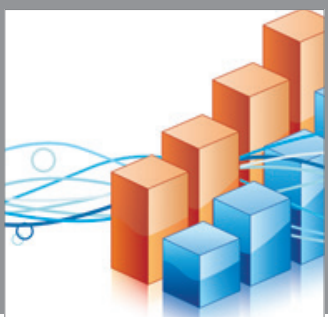

Advances in

Operations Research

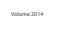

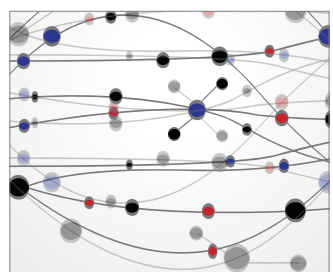

\section{The Scientific} World Journal
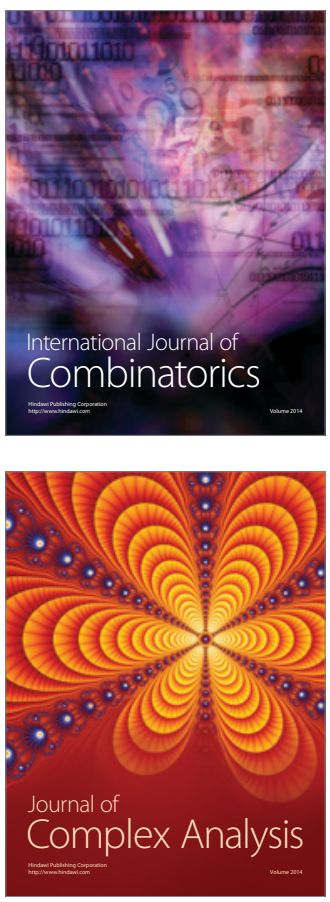

International Journal of

Mathematics and

Mathematical

Sciences
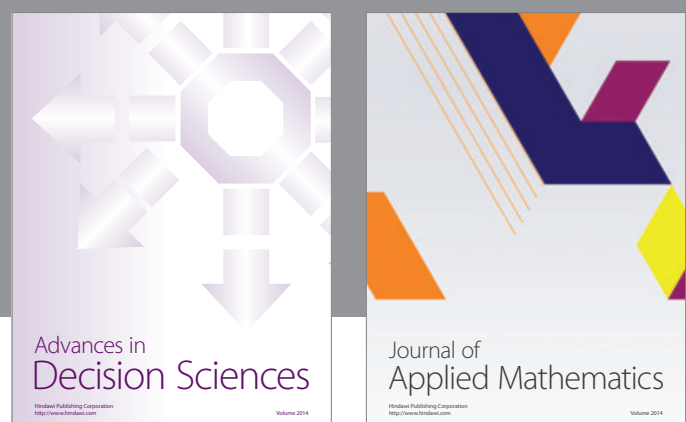

Journal of

Applied Mathematics
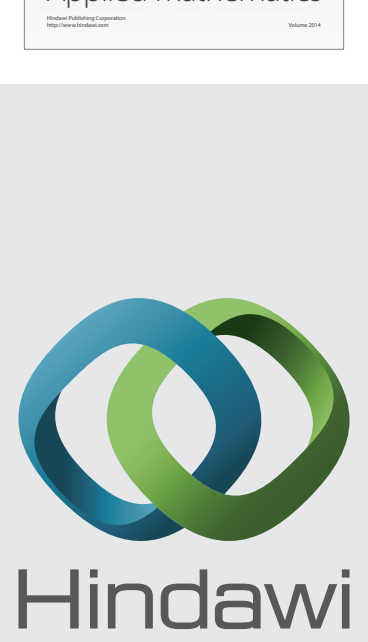

Submit your manuscripts at http://www.hindawi.com
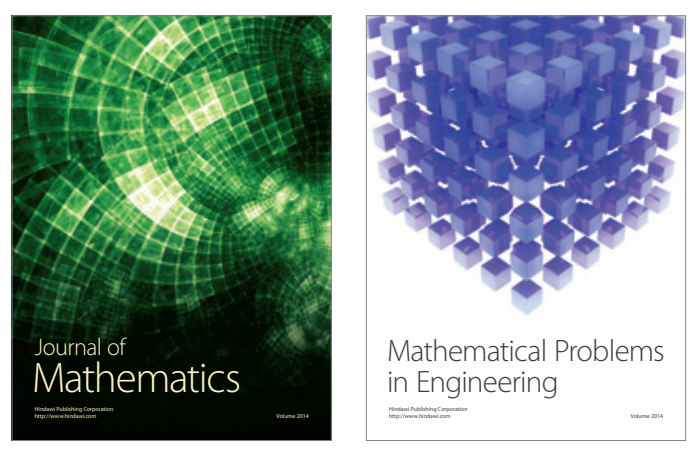

Mathematical Problems in Engineering
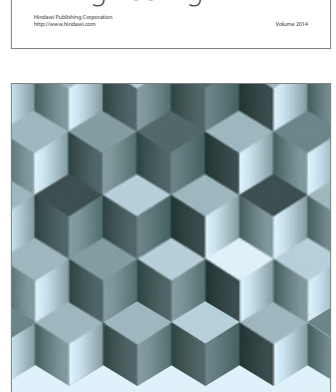

Journal of

Function Spaces
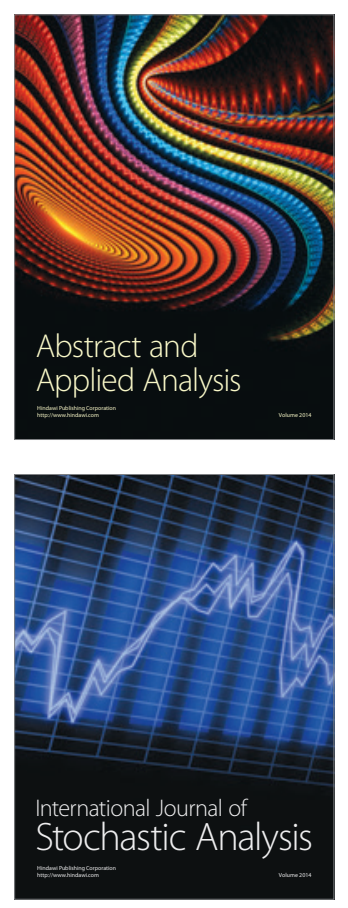

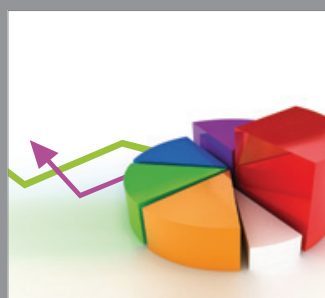

ournal of

Probability and Statistics

Promensencen
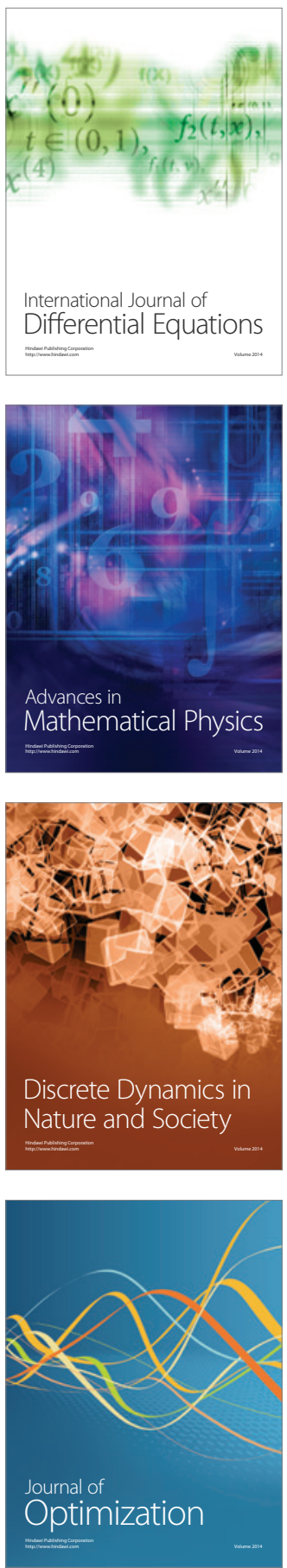